\title{
An Examination of Professor-Student Interactions, Stem Learning Challenges, and Student Adaptation Decisions During Covid-19 Pandemic
}

\section{Ms. Mercy Folashade Fash, North Carolina Agricultural and Technical State University}

Mercy Fash is an enthusiastic and determined researcher. She is currently a graduate student at North Carolina A\&T State University with the Applied Science and Technology Program. With a Bachelor's degree in Computer Engineering, a master's in Technology management and currently attaining a PhD in Applied Science and Technology, Mercy is a passionate STEM student who is purposeful about the success and well-being of other STEM students. She is currently working on other researches that would help understand the decision-making, and thinking processes of STEM students. Mercy has had the opportunity to work with great minded STEM scholars and researchers in the course of her career and has been exposed to real life experiences that have shaped her perspective on the relevance of STEM professions. Mercy is currently mentored by Dr. Andre Ofori-Boadu who has tremendous achievements in the STEM profession as a resourceful scholar and a researcher. Mercy has a learnt a lot from Dr. Andrea in the little time she has worked with her and still hopes to learn some more. Mercy is determined to find out possible ways to advance the STEM professions and also inspire young students to also see the relevance of the STEM professions. Overall, Mercy has a bright future in the research and as a STEM professional.

\section{Dr. Andrea Nana Ofori-Boadu, North Carolina Agricultural and Technical State University}

Dr. Andrea N. Ofori-Boadu is an Assistant Professor of Construction and Construction Management with the Department of Built Environment within the College of Science and Technology at North Carolina Agricultural and Technical State University (NCA \& T). Her research interests are in bio-derived cement replacement materials, delivery of sustainable built environments, and professional identity development in STEM students, particularly architecture, engineering and construction (AEC) women.

In February 2019, Andrea received the prestigious National Science Foundation NSF - CAREER award to research professional identity development processes in undergraduate AEC women. She has also received grants from East Coast Construction Services, Engineering Information Foundation, and the National Association of Home Builders.

In 2019, Andrea received the Outstanding Young Investigator award for both North Carolina A \& T State University and the College of Science and Technology. In 2018, she was selected as a 2018 National Science Foundation - NC A \& T ADVANCE IT Faculty Scholar. She also received the 2018 CoST Teaching Excellence Merit Award. Dr. Ofori-Boadu received both the 2017 NC A \& T - CoST Rookie Research Excellence Award and the 2017 North Carolina A \& T State University (NCAT) Rookie Research Excellence Award. Under her mentorship, Dr. Ofori-Boadu's students have presented research posters at various NCAT Undergraduate Research Symposia resulting in her receiving a 2017 Certificate of Recognition for Undergraduate Research Mentoring. In 2016, her publication was recognized by the Built Environment Project and Asset Management Journal as the 2016 Highly Commended Paper. Andrea has served as a reviewer for the National Science Foundation (NSF), Environmental Protection Agency (EPA), and several journals and conferences.

Dr. Ofori-Boadu engages in professional communities to include the American Society for Engineering Education (ASEE), the National Association of Home Builders (NAHB), and the National Association of Women in Construction (NAWIC).

In 2015, Dr. Ofori-Boadu established her STEAM ACTIVATED! program for middle-school girls. She also serves as the Executive Vice-President of Penuel Consult, Incorporated. She is married to Victor Ofori-Boadu and they are blessed with three wonderful children.

Ms. Rabiatu Bonku, North Carolina Agricultural and Technical State University

Mr. Wanya Alford, North Carolina Agricultural and Technical State University

Dr. Alesia Coralie Ferguson, North Carolina Agricultural and Technical State University 
Dr. Alesia Ferguson, is an Environmental Engineer and Public Health Specialist. She currently is the Chair of the Built Environment Department and oversees three programs: Geomatics, Environmental Health and Safety and Construction Management. Her research work focuses on children's environmental exposures and quantifying their related activities patterns. She was also a EPA lead trainer for the RRP regulations and a healthy homes specialists. She teaches courses such as Hazards Control, Industrial Hygiene, Fire Prevention, Exposure Analysis and more.

\section{Dr. Angela M. White, North Carolina Agricultural and Technical State University}

Dr. Angela Michelle White has an extreme passion for teaching and learning science. She earned a Bachelor of Science in Biology from the University of North Carolina at Chapel Hill, a Master of Science in Biology from North Carolina Agricultural and Technical State University, and a Doctor of Philosophy in Curriculum and Instruction with a concentration in Educational Psychology from North Carolina State University. Dr. White has served as an educator for 15 years at various levels and currently serves as the Assistant Dean of Student Success for the College of Science and Technology at North Carolina Agricultural and Technical State University. In this role she strategically develops and implements initiatives that promote the academic achievement and success of students within the College. Her current research interests, publications, and presentations give attention to racial identity, science identity, science selfefficacy, metacognition, and STEM achievement of African American students. As a strong advocate for the participation of African American females in STEM, Dr. White continuously engages in discourse and research that will promote greater access to STEM-related opportunities and recognition of African American females. 


\title{
An Examination of Professor-Student Interactions, STEM Learning Challenges and Student Adaptation Decisions during COVID-19 Pandemic
}

\begin{abstract}
The COVID-19 pandemic transformed STEM learning environments across U.S. institutions. However, the impact of this pandemic on learning and decision-making in students are yet to be fully understood. It is important to gain insights into student experiences during COVID-19 pandemic so that student and institutional resiliency can be improved during future pandemics. This research is part of a larger nationwide inductive research project with the purpose of developing theories to explain the learning experiences and decisions of undergraduate STEM students during the COVID-19 pandemic. A mixed-methods approach with purposive sampling was utilized to enroll 63 undergraduate STEM students from six U.S institutions. Data was collected through recruitment surveys, academic transcripts, and interviews. One-hour ZOOM interviews, gave research participants the opportunity to narrate their salient STEM learning experiences during the spring 2020 semester. Data was analyzed using the NVivo qualitative analysis software and Microsoft Excel for coding, categorizing, memo-ing, constant comparative analysis, and theme development. Also, Microsoft Excel was used to analyze demographic data from recruitment surveys and GPA data from the academic transcripts.
\end{abstract}

Results from the analysis of 30 coded interview transcripts revealed an emergent theme Professor-Student Interactions Impact Learning and Adaptation Decisions. The three key categories of this theme are: Professor-Student Interactions and Learning Challenges; Adaptation Decisions; and STEM Performance. The seven categories of Professor-Student Interactions are coded as: Online Instructional Delivery Methods; Professor Caring Attitudes; Professor Leniency; Professor Availability; Student Workloads; Professor Technology Proficiency; and Professor Teaching Resources. Positive professor-student interactions improve student learning experiences. Negative professor-student interactions worsen student learning challenges and are coded as: Illusion of Time, Procrastination; Lack of Focus; Challenge of Asking Questions; Poor Understanding; Poor Quality Assignments; Poor Intermediate Grades; Stresses; and Lowered Motivation. While most research participants experienced high stresses, a few of them experienced low or no stresses. To minimize the impact of COVID-related learning challenges on their STEM learning and performance, research participants made effective adaptation decisions coded as: Refined Scheduling; Alternate Learning Resources; Professor Office Hours; Teaching Assistants; Peer Collaboration; Relaxation Strategies; and Pass/Fail Options. Compared to the fall 2019 GPAs, the improved spring 2020 GPAs of research participants may be partially attributed to professor leniency, pass/fail option, and cheating.

Findings indicate that while STEM professors were adjusting to COVID-modified teaching and learning environments, many STEM students were developing a sense of selfdiscipline, self-teaching, and independence. They relied on both professor and non-professor generated resources to improve their own STEM learning and performance. Lessons learned and best practices for improved professor-student interactions and student adaptation decisions are discussed for potential replication in STEM communities for improved adaptability and resiliency during future pandemics. Future research will focus on quantifying the long-term effect of the COVID-19 pandemic on STEM performance. 


\section{Introduction}

The outbreak of the Coronavirus Disease 2019 (COVID-19) pandemic has had crucial impacts on all U.S. sectors. Businesses slowed down due to the stay-at-home home orders and directives issued by the Center for Disease Control and Prevention (CDC) to limit the spread of COVID19. The U.S. education sector was also impacted and institutions across the globe had to transition to distance learning education and university students returned home to finish up their spring 2020 coursework. Unfamiliar learning environments caused uncertainties in students and affected academic performance, internships, and general expectations of the future [1]. The learning consistency of students was affected with the physical closing of schools as students did not learn what they needed to learn, and possibly even lost previously gained knowledge [2],[3].

Institutions faced great challenges as they moved learning modules and resources to distance learning platforms within a short period of time to ensure that students still received quality education. Isolation from educational and social communities were also new norms as advised by the $\mathrm{CDC}$, and students had to get used to virtual platforms being their primary means of connecting to educational communities [3],[4]. Institutions implemented strategies to cope with the sudden changes in teaching and learning environments that that had suddenly became the new normal. Researchers continue to investigate the impacts of these transitions on student learning and academic performance across the globe [5],[6]. Some studies are focused on understanding the effects of online transition on relationships between professors and students. They encourage student interactions with professors, asking of questions during or after classes, visiting professor office hours for clarification on course matters, attending tutoring sessions for difficult courses, and having hands-on experience and face to face interactions with peers and professors [7],[8].

Considering that STEM students have unique learning experiences and environments, COVID-19 presented unique challenges to them. These challenges were serious and could slow down their learning, progression, graduation, and persistence into the STEM workforce. Consequently, it is important that their experiences are understood to improve student and institutional resiliency during future pandemics.

\section{Purpose}

This research study is a part of a larger research project which seeks to understand the learning experiences and decision-making processes in STEM students during the COVID-19 pandemic. Drawing from data obtained from STEM students, professors, and administrators, the purpose of this larger nationwide inductive research study is to develop theories to explain the learning experiences and decision-making processes of undergraduate STEM students during the COVID19 pandemic. The objective of this present research is to investigate the salient STEM learning experiences of undergraduate STEM students during the COVID-modified spring 2020 semester. 


\section{Method}

This research adopts a mixed-methods approach that utilizes the narrated experiences of research participants (RPs) to gain insights into the salient lived experiences of U.S. STEM students during the COVID-19 pandemic [9]. Drawing from sensitizing concepts, the interpretivist epistemology is adopted [9],[10],[11]. Institutional Review Board (IRB) approval was obtained prior to data collection. Recruitment surveys were used to obtain demographic data from RPs. Purposive sampling was utilized to select and enroll 63 STEM students with varying demographic characteristics from the six U.S institutions. These institutions comprised of HBCUs, PWIs, and MSIs located in various regions of the U.S. The primary form of data collection was through one-hour semi-structured interviews using the Zoom video communications software. The interviews gave RPs the opportunity to narrate their STEM learning experiences during the spring 2020 semester.

Before interviews began, RPs were informed that they could decline answering some questions and could withdraw from the interview at any time. They were also informed that the interviews will be video recorded and that their responses were confidential. Furthermore, their names and other identifying information would not be shared in any publications or presentations. During the interview, RPs were asked ten questions requiring them to explain their STEM learning experiences, decision making, and performance during the COVID-19 pandemic. Responses to these questions prompted further questions to obtain additional clarification needed for in-depth analysis. Zoom generated interview transcripts were checked and corrected to ensure accuracy. Also, RPs submitted their academic transcripts through email to the research team. Academic transcript reviews were used to confirm that research participants were currently enrolled in STEM programs in one of the six participating U.S. institutions. Furthermore, transcripts were used to estimate STEM performance.

The raw data collected from 30 transcribed interviews was analyzed using the NVIVO-12 qualitative analysis software for coding, categorizing, memo-ing, and constant comparative analysis. Transcripts were initially coded with special focus on the specific words, terms, and phrases used by the RPs during the interviews. Axial coding was then utilized to capture the meanings and themes emerging from the data. Microsoft Excel was used to analyze demographic and GPA data obtained from RPs.

Figures 1a-1d shows that most of the 30 RPs were between ages 18 and 25 years, had GPAs between 3.50 and 4.00, had annual household income less than $\$ 75 \mathrm{~K}$, and lived in 3-4 person households. These demographics demonstrate that the study captured students with varying characteristics. It appears that STEM students with high GPAs were more likely to selfselect and participate in research activities. 


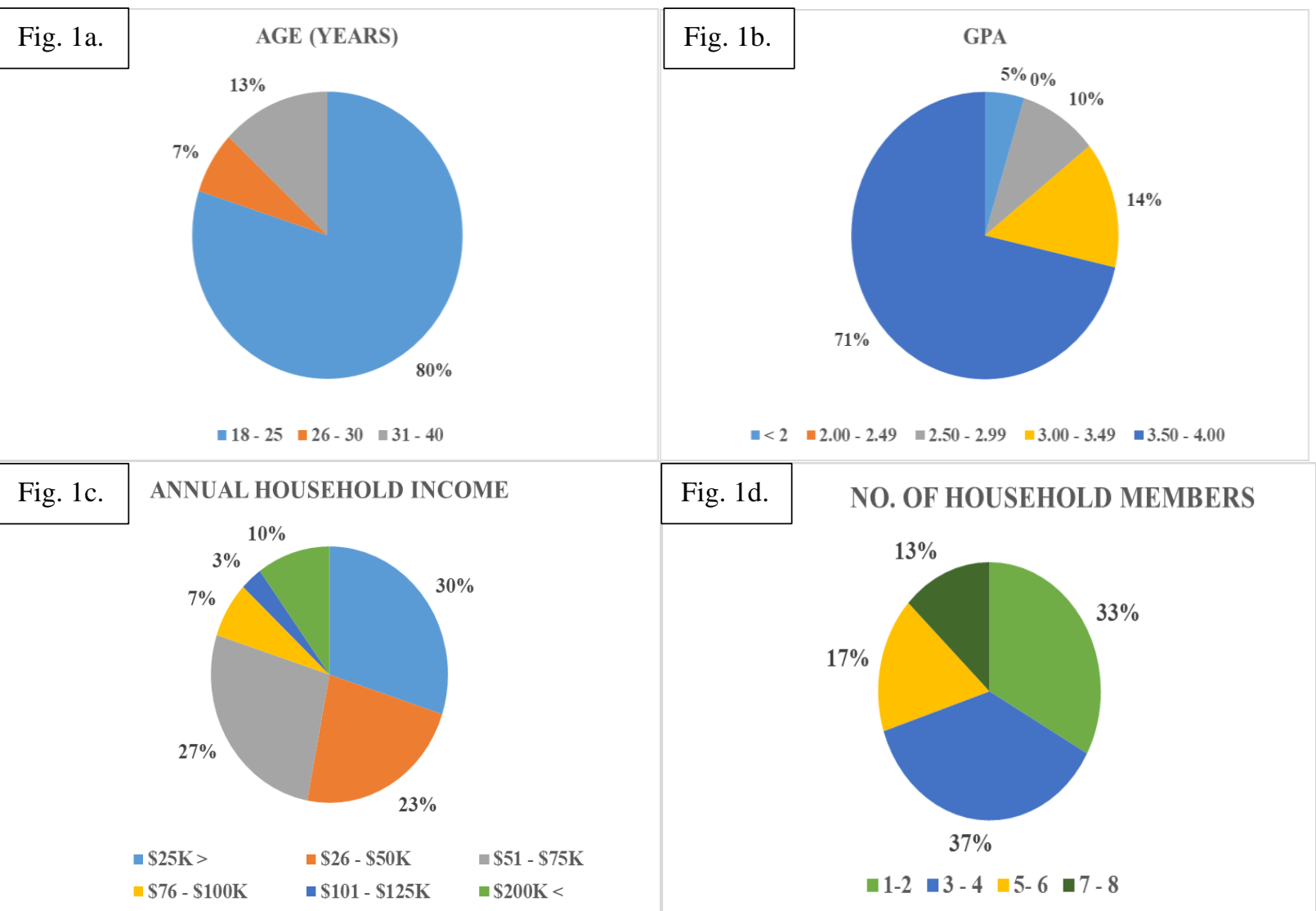

Fig. 1a. Age; 1b. GPA; 1c. Annual Household Income; 1d. Number of Household members

Figure 2 shows that RPs were mostly enrolled in science (40\%) and engineering (37\%) programs, with majority of them from biology and civil engineering programs.

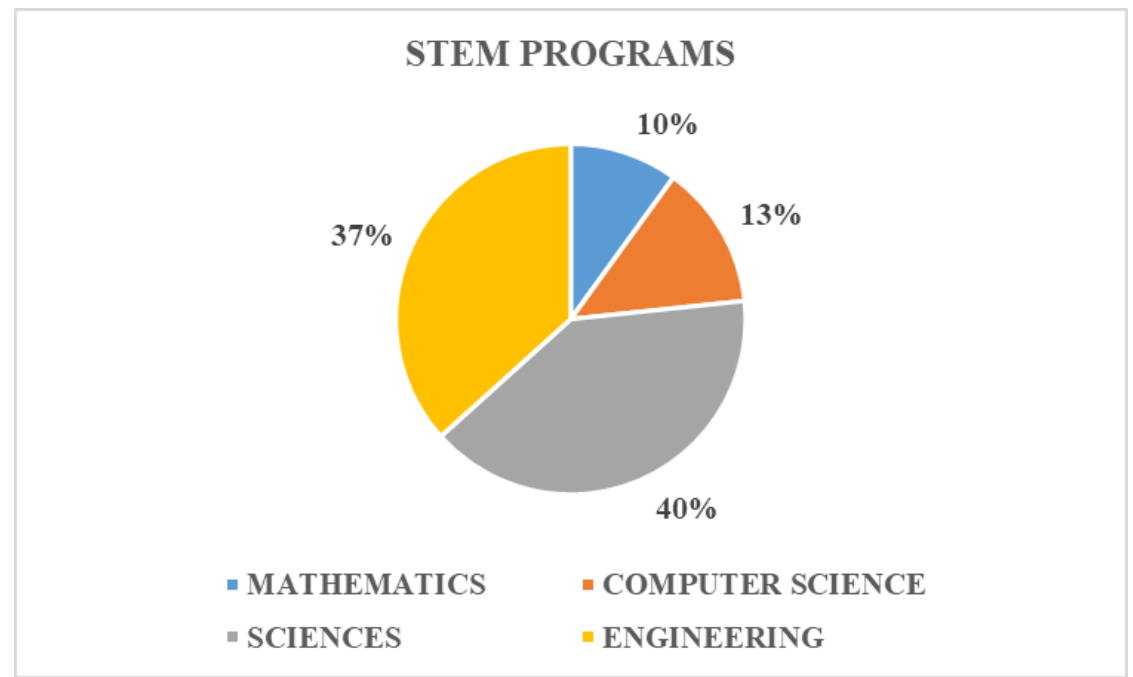

Fig. 2. STEM Programs of Research Participants 


\section{Results and Discussions}

Results from the analysis of 30 coded interview transcripts in this work-in-progress research revealed an emergent theme - Professor-Student Interactions Impact Learning and Adaptation Decisions. One hundred percent $(100 \%)$ of the research participants described and explained their thoughts, opinions, and feelings regarding their COVID-modified interactions with their STEM professors during the spring 2020 semester. Three key categories of this theme are: Professor-Student Interactions and Learning Challenges; Student Adaptation Decisions; and STEM Performance. The analysis of data obtained from thirty (30) coded interview transcripts demonstrated that RPs experienced positive and/or negative interactions with their STEM professors. Our results explain how professor-student interactions impacted learning, adaptation decisions, and performance of undergraduate STEM students. The results for the key categories supporting this emergent theme are discussed in subsequent paragraphs:

1. Professor-Student Interactions and Learning Challenges: Positive and negative professorstudent interactions impact learning:

(a) Online Instructional Delivery Methods: The three instructional delivery methods that RPs referenced during their interviews were coded as Synchronous, Asynchronous, and Hybrid methods. RPs experienced varying learning challenges in these instructional delivery methods as described below:

Synchronous method: Eighty-three percent (83\%) of RPs had synchronous courses which had an established class time. RPs could join through various virtual platforms and engage in professors' lectures. Some RPs, particularly those with other commitments and in different time zones, sometimes forgot to attend or were late for classes. RPs lamented that they missed their typical pre-COVID direct physical interactions with their professors and peers. One RP noted that "it was kind of hard to be that far away from my professors; and, also my study groups that I had before. It was just hard being so far away from them, because everybody had to go back home." Although RPs indicated that these interactions were not the same as pre-COVID campus learning environments, they appreciated the limited, but real-time interactions with professors and peers. Nevertheless, they expressed that it was very challenging to even ask questions in these virtual teaching platforms. An RP noted that 'I think in the class, you can actually see each other and have a conversation about what you're asking and what you're trying to say ... you're kind of, like you ask a question, but its 30 to 40 other students who have questions." RPs also missed the hands-on experiences of STEM learning. Considering that most STEM students are visual and tactile learners, the lack of hands-on STEM laboratory projects in synchronous courses negatively impacted their learning experiences. An RP stated “...We spend a lot of time at the farm usually at [Institution's Name], and just any hands-on science or labs that we would do, it's definitely missed out. We still do some of them online. But most of the hands on, you know, learning was missed out."

While some professors required RPs to turn on their cameras during online lectures; however, others did not. Some RPs preferred not to turn on cameras as they did not want to dress up nor show their surrounding spaces. With their cameras off, many RPs indicated that they got distracted, and sometimes even fell asleep during class. An RP noted that “...because my camera 
wasn't on, I would slip on my phone or I would step away for whatever reason, but, if it [camera] was on, it definitely would have been that pressure to, okay, my teacher knows that I'm present. If the camera was on, I would have been pressured to actually pay attention more." It was difficult for some RPs to stay focused during lectures. Without cameras on, some professors implemented different strategies to keep RPs engaged to minimize their distractions and stay focused on learning the STEM content. An RP stated, "I think the ones [professors] that didn't require your camera or your microphones on... They still found ways to keep you, um, in it. So, we will be ... he [professor] would ask the question, and he would be expecting like answers from, you know, what we just learned in it. So, he would basically count your participation as, um, if you participated in the group chats or, you know, so just to make sure you're paying attention and keeping up or if you have any questions. Um, in the live ones where they did turn on your camera, I think they were just making sure you know, you're not like walking away. So, um, it was kind of different, ... I paid more attention there because I'm like trying to answer questions and stuff like that." RPs admitted that if STEM professors had required them to turn on their cameras, it would have kept them more accountable and focused during online classes.

Asynchronous method: Forty percent (40\%) of the RPs had asynchronous classes, which had no fixed time for meeting and interacting with STEM professors. RPs mostly had to learn at their own pace using pre-recorded lecture videos and PowerPoint lecture notes from their professors. RPs were usually not motivated to watch the pre-recorded lectures. One RP stated that "... I just wasn't very driven to actually watch the lectures as often." They also complained about professors sharing PDF documents that were difficult to use and understand. It was difficult to learn with minimal supervision and support from STEM professors, and so many RPs had to figure out how to independently and correctly complete and turn in homework by the due dates. While asynchronous courses allowed RPs some flexibility with their schedules, it also created an "Illusion of Time", as one RP stated. Many RPs often thought that they had more time to complete their assignments, and this caused them to procrastinate and leave their assignments until the very last minute. Therefore, RPs turned in poor quality assignments which resulted in poor intermediate grades.

Hybrid method: 3\% of STEM students had hybrid classes initially, but these courses were later transitioned to online courses.

Overall, RPs confessed that while they did not particularly enjoy distance learning, it reduced some previous stresses associated with physically attending classes on campus. RPs enjoyed the fact that they could join their classes from anywhere and did not have to endure the hassle of waking up to get ready for campus classes. They did not even have to worry about rushing to campus early enough to ensure that they get parking spots. A commuter expressed the relief of not having to drive through traffic to school as she usually did during pre-COVID times. She noted, "... I saved a lot of time with commuting every day, because it would take me about actually 2 hours per day when I had classes on campus." Nevertheless, RPs indicated that these distance learning instructional methods minimized their interactions with their professors and peers, as well as their hands-on learning and laboratory experiences which had previously helped them better understand STEM concepts in the pre-COVID learning environment. One RP noted that, "a lot of the hands-on approaches to STEM learning were just eliminated." This lack of adequate interaction, particularly in STEM laboratory courses, reduced understanding of STEM content and ability to complete STEM course requirements. Poor grades from poor quality 
assignments compounded their stresses as students tried to cope with other non-education challenges associated with living in the COVID pandemic. High stresses in RPs caused $75 \%$ of them to express preference for campus courses. RPs felt they would have learned better on campus. One RP noted, "...the lab was laid out in a very vague way, so it was kind of hard to get the labs done anyway. What they did is, just take videos of the lab being done, and then we had to answer questions on what happened. Honestly, I know I would have learned more if it [lab] was in person." Overwhelmingly, RPs preferred synchronous over asynchronous courses because they believed that their increased human interactions with professors and peers improved their STEM learning and performance.

(b) Professor Caring Attitudes: RPs noted that STEM professors demonstrated varying levels of caring attitudes to students. Professor attitudes influenced students' learning experiences, relationships with professors, and confidence to reach out to professors when they needed assistance. These professor caring attitudes were coded as Caring Professors and Uncaring Professors.

Caring Professors: Fifty percent (50\%) of RPs indicated that their professors showed care to them during the pandemic. RPs appreciated professors who listened to their challenges in learning, checked to know how they were adapting, and encouraged them to persist in their difficult situations. An RP stated that "she was my first semester professor. But I went to her office hours a lot, so we built a relationship outside of class. So, she was the only one who reached out to me and asked me how I was doing and how my classes were going." Another RP stated that “..., with contacting my peers and my professors, I kind of build a stronger relationship with them because they will always see my name. You know, hey, she had a good question today in class or so email from her, so, I let me... it keeps my name on the radar. So, if I am having a problem where I need extra help, they'll be willing to help me, which was good for me because a lot of teachers would go the extra mile to help me if I needed, if I needed help, which was beneficial for me. And I don't think that would have happened if I were in class, if I were, you know, face to face because, um, because I wouldn't, you know, need that extra help, I think. So, it, it was good to have an extra relationship with the professors during this time." RPs built stronger relationships with their caring professors, and this was of great benefit to their general well-being.

Uncaring professors: Twenty-seven percent (27\%) of RPs felt that their professors did not show any care and did not understand the challenges that many STEM students were going through during the pandemic. These professors did not check on their students; not even when they failed to submit their assignment and complete their tests.

Overall, caring professors were able to reduce student stresses and improve their learning experiences; however, uncaring professors made learning very difficult for RPs.

(c) Professor Leniency: RPs indicated that professors had varying levels of leniency. These were coded as: Lenient Professors, Somewhat Lenient Professors, and Non-Lenient Professors. Lenient Professors: Thirty-seven percent (37\%) of RPs stated that their professors were lenient. These STEM professors extended due dates for assignments, quizzes, and other course requirements. They were also easier on grading RPs assignments. An RP noted that “... my 
professors were just a little bit easier on our grades, being that it was harder to learn. So, I would say that my grades were helped out a little bit from that." These RPs were grateful that their professors understood the challenges and stresses that the pandemic imposed on students.

Somewhat Lenient Professors: One RP indicated that professors were somewhat lenient, only in limited situations.

Non-Lenient Professors: Seven percent (7\%) of RPs indicated that their professors were not lenient on deadlines and did not understand students' situations during the pandemic. One RP noted that “... professors didn't think that they should have extended the deadlines. For example, one of my [STEM program] professors had an ongoing semester long project ... And those first early weeks of the transition period, we had the deadline - and it [Long Project] was still due and people were like oh he didn't do that. He was still strict about the deadline, so a lot of people missed out...Thankfully, I did it ahead of the time, but a lot of my classmates were upset about that and they went to the department head and told head how it was unacceptable." RPs with non-lenient professors experienced serious learning challenges and stresses.

(d) Professor Availability: RPs indicated that professors had varying levels of availability. These were coded as: Available Professors, Somewhat Available Professors, and Unavailable Professors.

Available Professors: Thirty-three percent (33\%) of RPs were appreciative of the fact that their professors were available, when they needed them. Professors responded effectively to their emails, communicated important information, were present during their office hours to answer questions, and aided students. An RP noted that "his office hours were like right after class, so any extra questions that I would have, I would just go straight to his office hours after to understand the content of whatever he recently taught." Another RP also stated that "I reached out to that professor a lot and there was a TA. She was a junior like me that taught the lab portion. I'd reach out to her quite a bit as well if I had questions about calculations or formulas or that I, you know, just because the online transition, it got kinda funky, so those two were they were good. They were also timely in their responses, so I knew that when I reached out to them that they were a good resource to have because I knew they'd get back to me right away."

Somewhat Available Professors: Thirteen percent (13\%) of RPs complained that their professors were sometimes available but did not maintain consistent communication with students.

Furthermore, when the professors communicated, sometimes it was unclear. One RP stated that, "...And so it's been like really chaotic. I remember my professors not giving us clear answers about whether or not all the tests will be canceled because of fears of cheating and so on, how that's going to work, so and like in the very beginnings, we did not even know, like what the course content would be? how class discussion would work?" Another RP noted that, "The [STEM program] department and professors could have made the process easier. I know a lot of them did not know what they were doing, and it was just thrown at them too. But I feel like a lot of them were like once we went online, it was you have to this, this, and this... without giving much instruction or direction. When I asked them questions, they would give me vague responses and leave it at that. Then I had to try to decipher things myself. So, I feel like they could have done better with instruction and direction on what to do." 
Unavailable Professors: Seventeen percent (17\%) of RPs complained that their professors were never available and did not communicate with their students. One RP complained that "So, I've actually had a couple of peers who said that their teachers weren't even getting back to them. They weren't responding to emails, which I feel, which is not very helpful, especially nowadays, everything is virtual. We can't get to the professor in person to ask them in a classroom. And with them not holding Zoom meetings like this, they're just putting notes online or submitting videos online, explaining the lecture. There's no direct communication between us and the professors. So, the communication between students and the professors definitely should be improved. For things like grades, the student has questions about an assignment or something like that. So, just communication in general between the professor and students should definitely be improved." RPs whose professors were mostly unavailable experienced high stresses and had to adapt by either reaching out to teaching assistants, collaborating with their peers, or utilizing alternate learning resources which were mostly available to them online.

(e) Student Workloads: RPs indicated that while some STEM professors increased assignments, other professors reduced assignments in their courses. These were coded as Overdrive and Underdrive.

Overdrive: Thirty percent (30\%) of RPs stated that their professors increased their workload in the spring 2020 semester with the mindset that since they were home, they had more time on their hands and so their professors wanted to keep their students busy. One RP complained saying “...Okay I felt like my teachers started to give a lot more busy work since we moved online. I think to them moving online, meant we had more free time to do more work, or either, think they had to actually make sure that we were doing work, so, they had to assign more. I'm not sure, but I just felt like there was a lot more busy work coming my way and a lot of other people felt like that too. It was just a great increase in the amount of work that we had to do on top of the already large pile that we had" This caused high stresses in RPs as they felt overwhelmed and had difficulty keeping up with their workload. One RP complained saying “... Ifelt like the teachers also had to add in a lot of like more work to make sure that we were actually doing it. So, like I already had a heavy class load. I think I was taking 17 hours at the time. So, that was already hard. Then they added on more work to that so. I just feel like it made it hard to effectively learn the material as far as labs go. There was obviously no real way you could do them with getting the same amount of like hands-on experience. So, it made it super harder and harder to learn."

Underdrive: Seven percent (7\%) of RPs stated that their professors reduced their workload. This gave RPs more time to focus on other things around them, spend more time with their significant others, and be able to complete STEM course requirements. They experienced lower stresses, while those in overdrive courses experienced higher stresses that had negative impacts on STEM learning.

(f) Professor Technology Proficiency: RPs observed that STEM professors had varying levels of proficiency in the utilization of educational technologies for distance education. They were coded as: Tech Savvy, Tech Sketchy, and Tech Awkward. 
Tech Savvy: 17\% of STEM students commended their professors for being technology savvy. They easily adapted to the distance learning transition and were able to teach efficiently online. These professors knew how to update assignments, tests, exams, and other learning materials in online educational systems such as Blackboard Educational System. They were able to use different virtual tools to demonstrate and explain STEM concepts. Consequently, RPs experienced fewer learning challenges and stresses.

Technology Sketchy: Thirteen (13\%) of RPs stated that their professors were not adequately technology savvy.

Technology Awkward: Twenty-seven (27\%) of the RPs complained that their professors were technology awkward as they demonstrated severe deficiency in using virtual teaching tools to deliver STEM content to their students. They did not know how to use the online resources adequately and their lack of knowledge and experience resulted in delays and mistakes in their courses. Therefore, their students struggled and experienced several learning challenges as they were not able to have access to learning resources needed for them to understand STEM content and complete course requirements in an effective and timely manner. It appeared that older professors were more likely to experience challenges in their use of technology because they had minimal pre-COVID experiences with virtual learning and working. One RP explained that '... kind of hoping everything would be kind of tech savvy, but a lot of- a lot of, um, older professors took a couple of weeks to definitely get a good flow of things and how Zoom worked or how to use their Blackboard or any other software that can help them teach. So, some professors, you know, their, their lecturers- they just, you know, they didn't do PowerPoints already. They didn't, you know, use technology [before COVID], so, it forced them, all of a sudden to use-technology was kind of a downfall for them and they were, you know, it took them time to learn how to use technology that could help them teach us."

The lack of technology proficiency in their professors and courses caused high stresses in RPs and lowered their motivation to learn as they were not getting timely access to the resources that they needed to learn and complete STEM course requirements. RPs strongly recommended that professors be provided training to enhance their online teaching capabilities. One RP noted that, “... not all teachers are trained to be online instructors, like they don't all know technology and using technology. I feel like there could be some type of training or sessions they can attend to understand how to use the software...Especially in the beginning, that was a lot of what was difficult because you're trying to learn but they [Professors] also don't know what they're doing. So, it's kind of hard adjusting."

Overall, it seemed that the tech savvy professors were usually younger professors and/or from disciplines that had provided them with pre-COVID virtual learning or working experiences that they effectively utilized during the COVID-19 pandemic.

(g) Professor Teaching Resources: While few RPs indicated that their professors had adequate teaching resources, many RPs had concerns about the adequacy of teaching resources. These were coded as: Adequate Teaching Resources and Inadequate Teaching Resources. 
Adequate Teaching Resources: Seven percent (7\%) of RPs indicated that their professors provided their students with adequate teaching resources that helped them through the semester. These RPs did not encounter serious learning challenges as they did not have to struggle to obtain resources needed to effectively learn STEM content.

Inadequate Teaching Resources: Thirteen percent (13\%) of RPs complained that their professors provided them with inadequate teaching resources. Their professors uploaded PowerPoint presentations without effective supporting resources, such as videos to explain complex calculations and analysis. These RPs suggested that it would have been better if the professors had white boards to demonstrate complex calculations in real-time during class or through videos. They wanted professors to find alternate ways of presenting more elaborate and clear explanations to students. Professors having inadequate teaching resources caused high stresses in students.

\section{Stresses: Negative professor-student interactions and learning challenges resulted in learning stresses in STEM students.}

Eighty percent ( $80 \%$ ) of RPs experienced high stress, 13\% experienced low stress, 3\% experienced no stress, and 3\% made no stress related comments. RPs noted that online learning was a struggle and stressful to them due to the learning challenges associated with distance learning environments and negative professor-student interactions during the COVID-10 pandemic. An RP described her online experience as terrible. She noted, "Terrible!! I hate online classes. I specifically avoid online classes and do everything I can to not have that. I don't think people [professors] read your questions. They have copy paste answers to things. It seems like I'll ask a question or I'll get an answer that had nothing to do with my question, like they didn't read my question where they didn't understand my question. I hate online. I don't think online should be a way people do college. I've had classes where the entire in person part was designed to be as hands off as possible because it's almost like the teacher just wanted it to be an online class, but couldn't get it that way 'cause they don't want to interact with students." Another RP complained explaining that "... It's always super stressful for me at the beginning just because I'm trying to get into a new routine with like what day things are due and with the long schedule I make... and really study for test because we just didn't do a very good job with that because I think we were all stressed and far away." RPs struggled with anxiety and fears that impacted their mental health and reduced learning and performance.

\section{Adaptation Strategies: Adaptation strategies improved STEM learning}

(a) Relaxation Strategies: Seventy-seven percent (77\%) of RPs tried to reduced stresses through relaxation strategies such as working out, taking breaks, meditation, reflection sheets, movies, family support, self-leniency, mental wellness visits, and other mental health strategies. One RP noted that, "Yeah, so, you know, I kind of, I forced myself to, uh, to at least get some physical activity. Even If I didn't want to or not, I just knew I'd feel a little better, I was able to focus a little better if I did."

(b) Peer Collaboration: Seventy percent (70\%) of RPs connected with their peers and study groups to enhance their understanding and learning of STEM content. One RP stated that, "we helped ourselves with Biology and chemistry, because those are the classes we're taking 
together. So, we'll do group video calls and watch a YouTube video and we'll talk about what they think about, what were some things, what I think, we'll bring it together. You know, Does it help during test to write out possible questions that could come out? And we call each other, you know, look at the questions. I'm like, this was my answer. I'll say this was my answer. We call lines and look for the actual answer, that's what we did."

(c) Refined Scheduling: To adapt effectively to synchronous and asynchronous instructional methods, $57 \%$ of RPs adopted various strategies to better manage their time so they can actively participate in their courses and complete course requirements. An RP noted that "I had to set like two alarm clocks just to get out of bed." RPs used alarms, google calendars and other electronic devices to help them better manage their time. With their improved time management, proactive RPs were more self-accountable, consistently attended classes, scheduled specific times to watch pre-recorded videos, participated in office hours, and completed their assignments."

(d) Alternate Learning Resources: Fifty-three percent (53\%) of RPs utilized alternate learning resources as their STEM professors were not providing them with adequate resources. RPs sourced alternate learning resources such as YouTube, eBooks, online tutoring, study groups, and other resources to improve their understanding of STEM content. One RP noted that, "...I relied on online sources. So, like YouTube videos and Khan Academy. I definitely leaned on those resources more than I did during pre-COVID school. So, I would YouTube how to solve chemistry equations... Definitely, I think that using YouTube and Khan Academy helped me." Alternate resources were effective in improve learning experiences and performance.

(e) Professor Office Hours: Forty-three percent (43\%) of RPs reached out to their professors during their office hours to obtain increased understanding of STEM content and access to other resources to improve their STEM learning. An RP stated that "Certainly reaching out to professors more and asking them for clarification and things...I think it's just really about using the technology to its maximum potential like if you were able to set up those Skype meetings with your professors if you're able to effectively communicate with your classmates that actually likes accomplish something you get learning done you'll get your projects done yeah."

(f) Pass/Fail Option: Twenty-seven percent (27\%) of RPs opted for the pass/fail option to maintain their GPAs. One RP noted that "well, I felt like I still learned an adequate amount, but because it was just a little bit lower, it was a smart idea to take it as satisfactory or as a pass just to help my GPA a little bit."

(g) Teaching Assistants (TAs): Ten percent (10\%) of RPs contacted TAs for resources and support to increase STEM learning. An RP noted that "The professor would like share his screen and then talk to us during the lecture and then they eventually set up some official like teachers assistants office hours where they were available for like, answering questions."

\section{STEM Performance: Effective adaptation strategies impacted STEM performance.}

The mean GPA obtained from the spring 2020 academic transcripts received from 21 RPs was 3.46. Compared to their fall 2019 GPAs, these RPs had a mean GPA increase of 0.49 . However, eight of the RPs opted for pass/fail options, which is an indication that they would have had 
lower GPAs otherwise. This apparent increase in grades may be partially attributed to professor leniency, pass/fail options, and cheating.

RPs missed physical and social aspects of STEM in-person learning on campus. They indicated through multiple statements that professor-student interactions and adaptation decisions influenced their STEM learning, understanding, performance, and grades. Although many RPs tried hard to stay motivated and complete their course requirements, they were constantly experiencing severe challenges and in a continuous struggle to improve their motivation to learn, understand STEM content, and improve STEM performance. One RP stated that, "I think that the motivation behind all my classes kind of changed. Just with all the atmosphere around the pandemic in general, it felt more like the classes were kind of a seminary very thing compared to everything else going on socially, and that it felt more like if in person, I was trying to excel, I was trying to do my best. But then during the pandemic, it feels more like you're just trying to get by. No motivation behind it and, I mean, you definitely want to try your best but for me, it felt, I just lacked a lot of motivation, especially towards like the last couple of weeks." Their lack of motivation was attributed to the COVID-modified STEM learning environments and the challenge of coping with the COVID-19 pandemic in general.

Some RPs were able to improve their STEM performance after persistently implementing effective adaptation strategies. One RP stated that, "Just the Google Cloud in general has been so helpful because it's enabled me to lay out my work as if I was in class and it links everything. One amazing thing is using Google Sheets, Google Docs and I can share it with my professors, with my classmates, I can share my calendar with my girlfriend if she wants to figure out when I'm free. So, just scheduling and being organized is such an important part of my personality and my academic success. So, that definitely helps my functioning and performance." Self-discipline played a critical role in maintaining good STEM performance. An RP stated, "I think that it really taught me self-discipline and being able to plan... That definitely helped me stay on top of it and not really slip behind that much." RPs indicated that they had become more independent and learned to self-teach as they did not have easy access to their STEM professors, TAs, and peers as they did during pre-COVID semester. An RP noted that "... I felt like I had to teach myself more. I think that when I had to teach myself that it helped me to understand the material better." Another RP stated, "Um, it also helped me become more independent ..., I had to learn to take things into my own hands and make sure that I'm keeping up on top of my own work and things like that." While self-disciplined and self-teaching RPs were able to maintain reasonable STEM performance and grades, other RPs had lower grades and had to opt for the pass/fail option for selected courses as they tried to minimize the impact of their low grades on their overall GPAs. One RP stated, “... I felt like I still learned an adequate amount, but because it was just a little bit lower, it was a smart idea to take it as satisfactory or as a pass just to help my GPA a little bit..."

RPs suggested that STEM professors should be provided with tools and training to support online STEM course delivery, reduce STEM student learning challenges and stresses, and improve STEM learning and performance. One RP noted, "I feel like offering instructors, say like, some sample tutorial maybe like a week-long training with online material would have been really helpful 'cause they have just been thrown into something that they have not ever done before." 
The results and discussions from this research show clearly that direct relationships exist among STEM professor-student interactions, STEM learning challenges, STEM student learning stresses, STEM student adaptation decisions, and STEM student performance as shown in the Professor-Student Interactions Model in Figure 3.

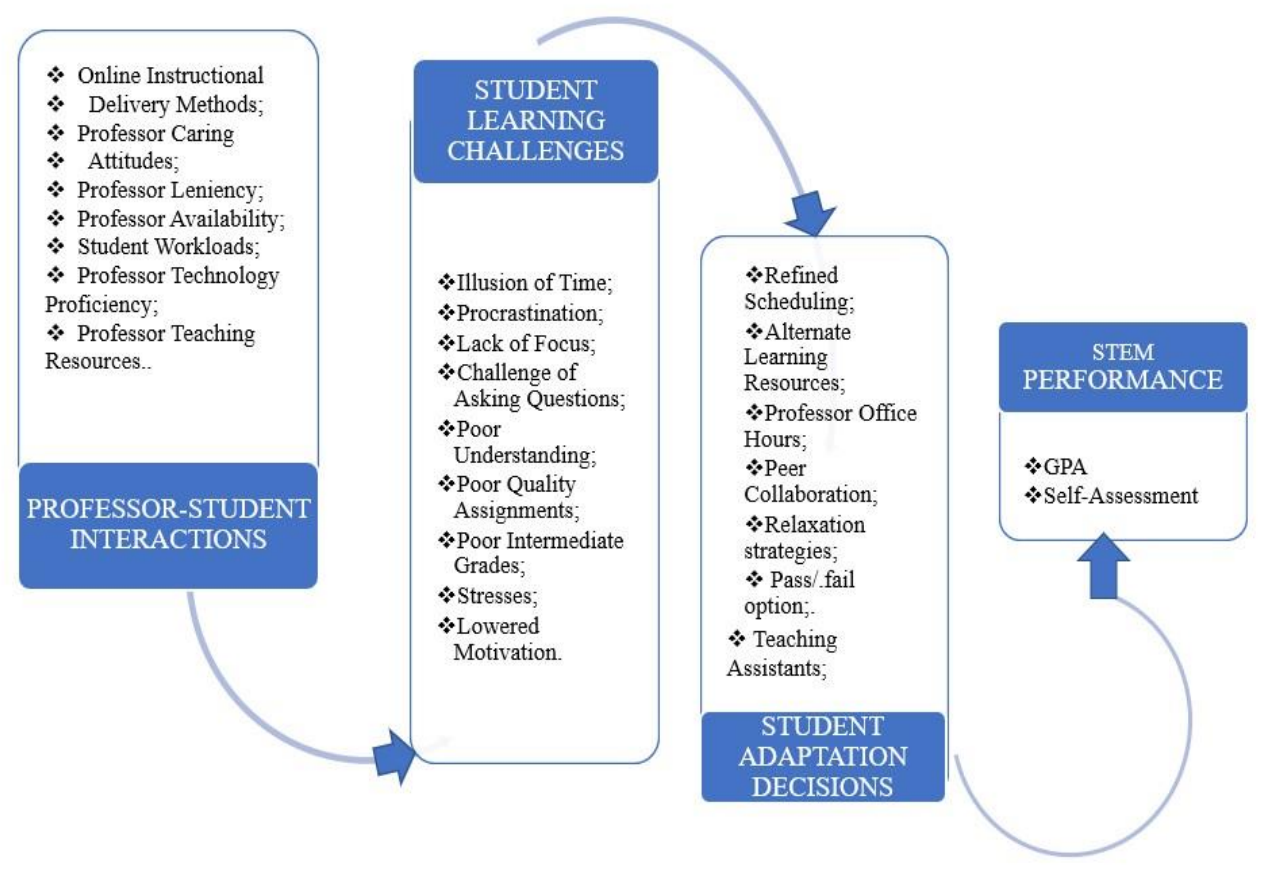

Fig. 3. STEM Professor-Student Interactions Model

\section{Summary}

STEM students had some positive interactions with their professors that enhanced their STEM learning and performance. However, there were negative interactions that generated stresses and reduced STEM learning and performance during COVID-19 pandemic. Early and effective institutional interventions and recommendations to improve STEM student learning experiences and performance during future pandemics include equipping STEM professors with instructional technologies, distance education training; administrative support, and teaching assistants. Also, institutional resiliency can be improved by implementing early interventions to identify and support struggling students and professors to enhance their capacity to be successful in distance learning environments. Institutions should provide targeted counselling services to meet the mental health needs of STEM students during pandemics. Future research will focus on quantifying the long-term effect of the COVID-19 pandemic on STEM performance.

\section{Conclusion and Future Work}

Findings indicate that while STEM professors were adjusting to COVID-modified teaching and learning environments, many STEM students were developing a sense of selfdiscipline, self-teaching, and independence to minimize the negative impacts of COVIDmodified learning environments on their motivation, learning, understanding, and performance. 
They relied on both professor and non-professor generated resources and support to improve their own STEM learning and performance. Insights from lessons learned and best practices can inform institutional interventions for improved STEM community adaptability and resiliency during future pandemics.

\section{References}

[1] E. M. Aucejo et al, "The impact of COVID-19 on student experiences and expectations: Evidence from a survey," Journal of Public Economics, vol. 191, pp. 104271, 2020. Available: http://dx.doi.org/10.1016/j.jpubeco.2020.104271. DOI: 10.1016/j.jpubeco.2020.104271.

[2] C. Son et al, "Effects of COVID-19 on College Students' Mental Health in the United States: Interview Survey Study," Journal of Medical Internet Research, vol. 22, (9), pp. e21279, 2020. Available: https://www.ncbi.nlm.nih.gov/pubmed/32805704. DOI: 10.2196/21279.

[3] T. Chamorro-Premuzic and A. Furnham, "Personality, intelligence and approaches to learning as predictors of academic performance," Personality and Individual Differences, vol. 44, (7), pp. 1596-1603, 2008. Available: http://dx.doi.org/10.1016/j.paid.2008.01.003. DOI: 10.1016/j.paid.2008.01.003.

[4] L. Li and J. P. Pitts, "Does it really matter? Using virtual office hours to enhance student faculty interaction," Journal of Information Systems Education, vol. 20, (2), pp. 175, 2009. Available: https://search.proquest.com/docview/200118830.

[5] M. Kuhfeld et al, "Projecting the Potential Impact of COVID-19 School Closures on Academic Achievement," Educational Researcher, vol. 49, (8), pp. 549-565, 2020. Available: https://journals.sagepub.com/doi/full/10.3102/0013189X20965918. DOI: 10.3102/0013189X20965918.

[6] P. Sahu, "Closure of Universities Due to Coronavirus Disease 2019 (COVID-19): Impact on Education and Mental Health of Students and Academic Staff," Curēus (Palo Alto, CA), vol. 12, (4), pp. e7541, 2020. Available: https://www.ncbi.nlm.nih.gov/pubmed/32377489. DOI: 10.7759/cureus.7541.

[7] M. M. Sanchez et al, "Student Perspectives on the University Professor Role," Social Behavior and Personality, vol. 39, (4), pp. 491-496, 2011. Available: https://search.proquest.com/docview/874937758. DOI: 10.2224/sbp.2011.39.4.491.

[8] C. Kim, E. Damewood and N. Hodge, "Professor Attitude: Its Effect on Teaching Evaluations," Journal of Management Education, vol. 24, (4), pp. 458-473, 2000. Available: https://journals.sagepub.com/doi/full/10.1177/105256290002400405. DOI: 10.1177/105256290002400405.

[9] K. Charmaz, Constructing grounded theory. 2nd ed. Los Angeles CA: Sage. 2014.

[10] B. Glaser and A. Strauss, The discovery of grounded theory. Chicago, IL: Aldine. 1967.

[11] A. Ofori-Boadu, V. Ofori-Boadu, J. Vanderpool, and D. Deng, "Nascent Professional Identity Development in Freshman Architecture, Engineering, and Construction (AEC) Women” 2020 Virtual American Society for Engineering Education (ASEE) Annual Conference \& Exposition, June 22 - 26, 2020. 2020, pp. 1-16. 